\title{
Challenging times for postgraduate medical education
}

There can rarely have been a more testing time for postgraduate medical education. We live in an era of measurement and assessment with the latter purportedly driving learning. In an increasingly sophisticated, team-based working environment there is a need to recognise and value both formal and informal learning. There is constant pressure on providing a service while protecting time - both personal and professional - for learning. Self-assessment, in its many guises, has enormous limitations and is increasingly challenged by the call for 'verifiable evidence', ' whatever that may be, however it may be judged, and never mind costed.

Knowledge, or more accurately its acquisition and application, has never been more readily available and, without the appropriate skills, more difficult to keep abreast of. Critical thinking (separating the wheat from the chaff), giving and receiving feedback, and communication in its widest sense (verbal, non-verbal, and written), are all skills which help us collectively make sense of and share with others the necessarily complex world in which we work. Googletype search engines integrated into large databases with information ranked on the basis of relevance and quality are major advances in simplifying the application of best evidence for the more technologically-challenged. ${ }^{2,3}$

So much of our day-to-day work is facilitated by electronic means. For some, e-anything is an addiction, for others a necessary evil, and for most of us a recognition that e-learning does well on the hype but the jury is still out on its relative merits over more traditional methods of learning. ${ }^{4}$

\section{CPD AND THE CURIOUS MIND}

Where does this leave us when confronted with credits for our continuing professional development (CPD), presenting 'evidence' for revalidation, and ensuring that at least some of the profession retains an independence of spirit to allow a continual challenge to the status quo? The need to foster curiosity against a background of bureaucracy and regulation will test the resolve of most medical educators. Ticking a box is the perfect antidote to the curious mind.

Appropriate to encouraging curiosity is the growth of cognitive science in medical education. There is now a clear understanding of clinical decision making and, particularly, the difference between the relative novice's and the more experienced clinician's strategies in reaching an appropriate diagnosis. ${ }^{5} \mathrm{CPD}$ has an exciting opportunity in supporting strategies for reducing errors in clinical reasoning, such as encouraging both didactic and experiential learning; providing appropriate and timely feedback, such as through clinical audit and significant event analysis; and by encouraging a change in ethos where seeking advice without fear or ridicule becomes the norm. ${ }^{6}$ 'Thinking aloud' should be encouraged for all doctors. The role of a skilled appraiser in facilitating this process cannot be under-estimated.

\section{THE UNCERTAIN EVIDENCE FOR EDUCATIONAL INTERVENTIONS}

The effect of adult learning theories that underpin many educational interventions has not been thoroughly evaluated. The reasons for this are many and complex but the ill-defined role and variable quality of educational research have been cited. ${ }^{7}$ Three Cochrane reviews into the effects on professional practice and healthcare outcomes of local opinion leaders, ${ }^{8}$ educational outreach visits ${ }^{9}$ and continuing education meetings and workshops $^{10}$ have shown only small and modest improvements. All demonstrate the need to consider a more eclectic approach to the design of studies such as inclusion of participatory action research to address the complex interplay between learners and their environment.
One consequence of this is the extra burden imposed on appraisers and educators alike. Although a proportion of appraisers have some formal educational background, such as GP training or as a tutor, there is an increasing imperative for the appraisal and educational communities to work closely together to exploit the evidence-based educational opportunities that do exist.

\section{PROFESSIONALISM AND THE RISK OF MIXED MESSAGES}

Revalidation is the medical profession's response to the place of values and accountability in exercising the privilege of professional independence. ${ }^{11}$ The central role of appraisal in the revalidation process puts the appraiser in the position of having two possibly conflicting roles that of mentor and judge. The skills needed by appraisers and educationalists alike to judge the quality of educational material being presented at an appraisal, and, where necessary, make suggestions for improvement, have yet to be defined. The training costs for appraisers and appraisees will be substantial. If there is an ethical imperative for lifelong learning to be one of the profession's pillars there is a consequent ethical need to fully resource a robust road to revalidation.

\section{SUPPORTING THE RCGP}

Achieving a portfolio of evidence that is both worthwhile in terms of learning outcomes and sufficient for the regulators will, by definition, test the skills of the appraisal and medical education communities. The leadership role of the Royal College of General Practitioners in guiding the sensitivities and expectations of revalidation should be given constructively critical support. Given that all doctors are teachers and learners throughout their career, it has never been more important to understand the strengths and limitations inherent in postgraduate medical education in striving for a balance in a doctor and 
patient-centred approach to CPD and revalidation. Informed by innovative and robust research, a more rational debate can ensue. Honesty about the true cost, skills needed, and consequences is paramount. Postgraduate medical education has the chance to rise to the challenge of balancing regulatory needs with a healthy curiosity.

\section{Murray Lough,}

Lead (Educational Research), NHS Education for Scotland, Glasgow

\section{Provenance}

Commissioned; not peer reviewed

\section{REFERENCES}

1. Secretary of State for Health. Trust, assurance and safety - the regulation of health professionals in the 21st century. CM7013. London: The Stationery Office, 2007.

2. NHS Evidence. http://www.evidence.nhs.uk (accessed 8 Jul 2009).

3. Knowledge for Care Scotland. http://www.knowledge.scot.nhs.uk (accessed $8 \mathrm{Jul}$ 2009)

4. Cook DA, Levinson AJ, Garside S, et al. Internet-based learning in the health professions: a meta-analysis. JAMA 2008; 300: 1181-1196.

5. Eva KW, Hatela RM, Le Blanc VR, Brookes LR. Teaching from the clinical reasoning literature: Combined reasoning strategies help not with diagnosticians overcome misleading information. Med Educ 2007 41(12): 1152-1158.

6. Scott IA. Errors in clinical reasoning: causes and remedial strategies. BMJ 2009; 338: b1860.

7. Todres M, Stephenson A, Jones R. Medical education research remains the poor relation. BMJ 2007; 335: 333-335.

8. Doumit G, Gattellari M, Grimshaw J, O'Brien MA. Local opinion leaders: effects on professional practice and healthcare outcomes. Cochrane Database Syst Rev 2007; 1: CD000125.

9. O'Brien MA, Rogers S, Jamtvedt G, et al. Educational outreach visits: effects on professional practice and healthcare outcomes. Cochrane Database Syst Rev 2007; 4: CD000409.

10. Forsetlund L, Bjorndal A, Rashidian A, et al. Continuing educational meetings and workshops: effects on

professional practice and healthcare outcomes. Cochrane Database Syst Rev 2009; 2: CD003030.

11. Irvine D. The performance of doctors. I: professionalism and self-regulation in a changing world. BMJ 1997; 314: 1540-1542.

DOI: 10.3399/bjgp09X453738

ADDRESS FOR CORRESPONDENCE

\section{Murray Lough}

NHS Education for Scotland, 89 Hydepark Street, Glasgow, G3 8BW E-mail: murray.lough@nes.scot.nhs.uk

\section{Being a good clinician is not enough: doctors as employers and practices as organisations}

It is now accepted in general practice that we should incorporate the evidence derived from biomedical research into our practice, and both current contractual and proposed governance arrangements are designed to encourage this.

The paper in this issue of the BJGP by Hewitt et $a l^{1}$ reminds us of the additional importance of applying evidence to the overall service that we provide as well as to the narrow medical content of our consultations. Focusing on the detail of receptionist-patient interactions, Hewitt and her co-authors point to some of the contexts in which misunderstanding, miscommunication, and ultimately dissatisfaction may arise. They demonstrate that receptionists tend to use a limited repertoire of styles of communication, and that some of these styles are more prone than others to generate misunderstandings or miscommunications. This is important because such miscommunications, especially if repeated in subsequent visits to the practice, may build up to generate significant patient dissatisfaction; in the competitive environment currently facing general practice this could become a real problem.

The obvious approach to address this danger would be via staff training, and the paper by Hewitt et al ${ }^{1}$ could nicely be used as a teaching aid for in-house reception training; seeing dysfunctional exchanges written down can be very enlightening.

This draws attention to a wider issue: clinician-patient interactions do not represent the totality - or even the most important part of - a patient's overall interactions with the practice, and this is something that should be taken into account by partners as practice owners. Negotiation with receptionists, requests for repeat prescriptions, discussions with secretaries about Choose and Book appointments: all these represent opportunities for good or bad patient experiences.

As the complexity of the care that we provide increases, modern general practices have become quite large organisations, with a significant number of employees, and I would argue that we can no longer get away with simply appointing a practice manager and delegating staff training to that role. Issues such as violence against staff (see the article by Magin et al in this issue of the $B J G P^{2}$ ) and the stresses that receptionists experience $^{3}$ are important topics that partners should consider when they think about the development of their staff. Furthermore, just as we look for evidence about the clinical care that we provide, so we should engage with the extensive literature about behaviour in organisations to garner ideas about how this should be done.

The discourse analysis method used in Hewitt et al's study reminds us that if we 